\title{
Construção e validação de indicadores de avaliação de práticas de controle e prevenção de infecção do trato urinário associada a cateter*
}

\author{
Validation of indicators for controlling and preventing catheter-associated urinary tract infection
}

Validación de in-dicadores de control y prevención de infección del tracto urinario asociada a catéter

\section{Márcia Vanusa Lima Fernandes ${ }^{1}$, Rúbia Aparecida Lacerda², Nédia Maria Hallage ${ }^{3}$}

\section{RESUMO}

Objetivo: contribuir com uma nova modalidade de avaliação de qualidade de práticas de controle de infecção hospitalar do trato urinário associada a cateterismo. Métodos: estudo de desenvolvimento metodológico, consistindo de elaboração cientificamente fundamentada e validade de conteúdo de três indicadores de avaliação. A validade de conteúdo foi realizada por especialistas e referiu-se ao julgamento dos indicadores em quatro etapas: manual operacional; atributos de conjunto; atributos de componentes; relevância dos seus componentes. Resultados: dois indicadores foram validados ao obterem consenso favorável mínimo e ajustados conforme as sugestões apresentadas. O terceiro, mesmo sendo julgado relevante, não obteve consenso mínimo em duas etapas e não foi validado. Conclusão: o método de validação utilizado mostrou-se eficaz, permitindo concluir que a importância de uma dada prática não é condição suficiente para sua avaliação, se sua construção não for validada, a fim de ser aplicada de maneira objetiva e inequívoca.

Descritores: Infecção hospitalar; Trato urinário; Cateteres de demora; Indicadores de serviços

\begin{abstract}
Objective: to contribute to a new way to evaluate quality of care for controlling and preventing nosocomial infection associated with urinary catheterization. Methods: a methodological design was used to evaluate the content validity of three indicators for controlling and preventing urinary catheter-associated infection. Specialists in the management of urinary tract infection evaluated the content validity of the indicators using the following phases: operationalization; attributes of the content as a whole; attributes of specific content components; and, relevance of the specific components to the indicator. Results: only two indicators were considered to have appropriate content validity. The third indicator, which was classified as relevant, did not achieve a minimum consensus in two phases, which suggests inappropriate content validity. Conclusion: this methodological study was effective in determining whether or not three indicators had appropriate content validity for controlling and preventing urinary tract infection. This is an important process to undergo prior to adopting any indicator for use in patient care.
\end{abstract}

Keywords: Cross infection; Urinary tract; Catheters, indwelling; Indicators of health services

\section{RESUMEN}

Objetivo: contribuir con una nueva modalidad de evaluación de la calidad de las prácticas de control de infección hospitalaria del tracto urinario asociada a cateterismo. Métodos: estudio de desarrollo metodológico, consistente en la elaboración científicamente fundamentada y validez de contenido de tres indicadores de evaluación. La validez del contenido, referente al juicio de los indicadores, fue realizada por especialistas en cuatro etapas: manual operacional; atributos de conjunto; atributos de componentes; relevancia de sus componentes. Resultados: los indicadores fueron validados al obtener consenso favorable mínimo y ajustados conforme a sugerencias realizadas. El tercero, a pesar de haber sido juzgado como relevante, no obtuvo consenso mínimo en dos etapas y no fue validado. Conclusión: el método de validación utilizado se mostró eficaz, permitiendo concluir que la importancia dada a una determinada práctica no es condición suficiente para su evaluación si su construcción no es validada, a fin de ser aplicada de manera objetiva e inequívoca.

Descriptores: Infección hospitalaria; Tracto urinario; Sonda a permanecia; Indicadores de servicios

\footnotetext{
* Extraído de Dissertação de Mestrado que compõe o Projeto Geral de Políticas Públicas intitulado "Indicadores de avaliação e diagnóstico de práticas de controle de infecção hospitalar de serviços de saúde do Estado de São Paulo: construção e validação”.

${ }^{1}$ Mestre em enfermagem pelo Programa de Pós-Graduação em Enfermagem na Saúde do Adulto da Escola de Enfermagem da Universidade de São Paulo - USP - São Paulo (SP), Brasil.

${ }^{2}$ Enfermeira. Professora Livre Docente da Escola de Enfermagem da Universidade de São Paulo - USP - São Paulo (SP), Brasil; Coordenadora do projeto.

${ }^{3}$ Mestre em Moléstias Infecciosas, Professora. Auxiliar de Ensino II da Fundação Medicina do ABC. Santo André (SP), Brasil.
} 


\section{INTRODUÇÃO}

O trato urinário (ITU) é um dos sítios mais comuns da infecção hospitalar (IH), representando cerca de 40\% de sua totalidade. A sua ocorrência resulta em repercussão econômica, potenciais complicações, seqüelas e danos intangíveis ${ }^{(1-7)}$.

Os principais fatores de risco associados às ITU são: sexo feminino, idade avançada, disfunções anatômicas e fisiológicas do trato urinário e doenças subjacentes severas, como diabetes. Mas, sem dúvida, a grande maioria destas infecções, cerca de $80 \%$, está associada ao cateterismo do trato urinário e sua duração ${ }^{(8)}$. As principais medidas de prevenção de ITU associada ao cateter, baseadas em estudos científicos, estão reunidas nos guias de recomendações do Centro de Controle e Prevenção de Doenças (CDC) dos Estados Unidos ${ }^{(4)}$ e Britânico ${ }^{(9)}$.

As atividades atualmente predominantes de controle de $\mathrm{IH}$, inclusive de ITU, centralizam-se na vigilância epidemiológica, com uso de indicadores epidemiológicos de resultados, ou seja, mensuração do quão freqüentemente um evento acontece. Mas tais indicadores não avaliam, de maneira prospectiva, a qualidade das práticas assistenciais relacionadas com $\mathrm{IH}$ e, portanto, não intervêm na sua prevenção. Há praticamente um consenso atual sobre a necessidade de novos indicadores que realizem não apenas vigilância epidemiológica, mas que avaliem a qualidade das práticas de $\mathrm{CIH}$.

Uma maneira para avaliação da qualidade de práticas assistenciais é a construção de indicadores clínicos, que constituem medidas quantitativas de resultados desejáveis ou indesejáveis de um dado processo ou sistema, medidos de forma contínua ou periódica, para que se verifique o alcance de objetivos ${ }^{(10)}$. São também definidos como variáveis de características ou atributos capazes de sintetizar, representar e ou dar maior significado ao que se quer avaliar ${ }^{(11)}$. Auxiliam na mensuração de mudanças e são utilizados quando não podem ser medidas diretamente, mostrando uma realidade para quem não está inserido nela. Contudo, nem sempre é possível descrever um cenário com um único indicador; utilizase, então, um conjunto de indicadores que contemple todos ou os principais aspectos da prática ou do procedimento que se busca avaliar ${ }^{(12)}$.

Os indicadores são constituídos de numerador e denominador e podem incorporar as três dimensões clássicas de avaliação de qualidade em saúde: estrutura, processo ou desempenho e resultado ${ }^{(13)}$. A vantagem de um tipo de avaliação sobre outro está na adequação do seu uso, conforme o evento a ser medido. Avaliações estruturais possibilitam uma base de capacidade, mas a conformidade e seu uso não asseguram que a alta qualidade está ocorrendo ${ }^{(13)}$. As processuais são avaliações críticas de qualidade, mas não estão bem desenvolvidas em comparação com as de resultados, sendo boas somente se os processos selecionados se relacionarem com resultados importantes e puderem ser mudados ${ }^{(14)}$. As de resultado incorporam o princípio da redução de variabilidade em termos relativos, monitorando a eficiência e a efetividade, em termos de um limite máximo e mínimo aceitável, estimando os fatores de risco que determinam a boa ou a má qualidade, sendo, portanto, mais útil para julgamento do que para melhoria de qualidade ${ }^{(9)}$.

A construção de indicadores, de acordo com a literatura científica ${ }^{(10,13-19)}$, é constituída de várias etapas. A primeira delas é a definição das ações a serem avaliadas, a partir dos seguintes critérios: importância da ação a ser avaliada, de acordo com sua contribuição significativa na morbidade e mortalidade (alto risco), associação com altos índices de sua utilização ou realização (alto volume); alto custo na sua execução; potencial para a implementação e monitoração de desempenho de qualidade, com evidência de que a qualidade é variável ou sub-padronizada (evidência); grau de controle dos mecanismos para a implementação da ação (melhoria contínua de qualidade); necessidade do seu controle e qualificação por norma ou legislação governamental (obrigação legal).

A segunda etapa é a constituição do grupo que construirá os indicadores, preferentemente com experiência na prática a ser avaliada. A terceira é o treinamento do grupo para a construção dos indicadores. A quarta é a busca de fundamentação para a construção do conteúdo dos indicadores, cujos principais recursos são: evidência científica (revisão sistemática, de preferência com metanálise); diretrizes clínicas elaboradas por sociedades de especialistas ou agências governamentais; estudos científicos isolados e bem controlados metodologicamente, preferentemente randomizados; estudos de caso; sistemas integrados para elaboração de indicadores de qualidade; combinação de fundamentação teórico-científica com métodos de consenso. Os métodos de consenso fundamentam-se em opinião de especialistas, tanto com relação à evidência da fundamentação, quanto à capacidade do indicador de medir o que se propõe a medir.

Este estudo pretendeu contribuir com novas práticas de controle e prevenção de IH, por meio da elaboração e validação de indicadores clínicos que permitam avaliar aspectos dos procedimentos de inserção, permanência e manutenção do cateterismo vesical que se relacionam com o risco de ocorrência de ITU.

\section{MÉTODOS}

Estudo de desenvolvimento metodológico de elaboração e validação de indicadores de avaliação em saúde. Ou seja, "refere-se às investigações dos métodos 
de obtenção, organização e análise dos dados, pela elaboração, validação e avaliação de instrumentos e técnicas de pesquisa"(20).

Os instrumentos, neste caso, referem-se aos indicadores de avaliação de práticas de controle e prevenção de ITU associada a cateter, submetidos às seguintes etapas metodológicas: seleção e construção dos indicadores; fundamentação teórico-científica; validação.

A primeira etapa iniciou-se com a formação e o treinamento do grupo de pesquisadores, todos com experiência na área de $\mathrm{IH}$, para a definição e construção dos indicadores, que resultaram nos seguintes: 1 Indicação e Permanência do Cateterismo Vesical (IUIC); 2 - Manutenção do Cateterismo Vesical (IUMN); 3 Infra-Estrutura para Procedimento de Cateterismo Vesical (IUIF). Os indicadores 1 e 2 são de processo e o 3 é de estrutura. Cada um deles contém um construto teórico (manual operacional) e uma planilha para aplicação da avaliação. Cada indicador apresenta o que é esperado como prática adequada, de maneira que seja possível comparar com o que é realmente realizado, e obter o índice de conformidade em um dado serviço.

A fundamentação teórico-científica, segunda etapa, baseou-se principalmente nas recomendações de melhores categorias de evidência, estabelecidas por entidades americanas e britânicas responsáveis pela elaboração de diretrizes para práticas clínicas ${ }^{(4,9)}$.

Para a validação científica dos indicadores, terceira etapa, utilizou-se o método de Validade de Conteúdo, pelo julgamento de especialistas, referindo-se tanto à consistência e valor de cada indicador para avaliar as práticas a que se destinam, em termos de capacidade e amplitude para mensurar a qualidade das mesmas, quanto à análise de sua capacidade para orientar, captar, mensurar e analisar os dados.

$\mathrm{Na}$ composição do grupo de especialistas, a porção quantitativa acatou a literatura pertinente ${ }^{(21)}$ e a qualitativa garantiu representatividade quanto a: principais categorias profissionais envolvidas diretamente com o CIH (4 enfermeiros e 5 médicos); ampla experiência no CIH; atuações em várias instâncias, desde a prática assistencial (7), acadêmica (2), órgãos governamentais regulamentadores (2) e entidade associativa (3). Ressalte-se que número de áreas de atuação é maior do que o do total de especialistas, pelo fato de alguns deles atuarem concomitantemente em mais de uma destas áreas.

A técnica de trabalho consistiu no preenchimento individual do instrumento de julgamento pelos juízes, sendo que um não sabia quem eram os demais, no período de novembro de 2004 a fevereiro de 2005.

O julgamento consistiu de quatro fases: I - Conteúdo do manual operacional, com respostas afirmativas ou negativas aos seus itens constitutivos; II - Atributos dos conjuntos dos indicadores, conforme a escala psicométrica: (1) não contempla o atributo, (2) incapaz de contemplar o atributo sem revisão, (3) contempla o atributo, mas precisa de alteração mínima, (4) contempla o atributo; III - Atributos dos componentes individuais dos indicadores, com respostas negativas ou afirmativas; IV - Valoração de relevância dos componentes, apenas do indicador 3, conforme a escala psicométrica: (1) não relevante, (2) pouco relevante, (3) relevante, (4) muito relevante.

O projeto de pesquisa foi aprovado pela Comissão de Ética em Pesquisa da Escola de Enfermagem da USP, além de ter obtido concordância dos participantes após apresentação dos termos de compromisso e de consentimento livre e esclarecido.

Foram considerados aprovados os julgamentos de opiniões convergentes, com nível favorável mínimo de $75 \%$, portanto, próximo do máximo verificado na revisão de literatura, que variou de $50 \%$ a $80 \%{ }^{(22)}$ Quando abaixo de 75\%, consideraram-se os comentários e sugestões para a não conformidade, a possibilidade de ajuste, com ou sem o retorno aos participantes, ou ainda, a supressão de aspectos sob avaliação que não alcançassem este índice. Nos julgamentos de atributos com escalas psicométricas, consideraram-se aprovados no consenso de $75 \%$ apenas os atributos que obtiveram pontuações 3 ou 4 .

\section{RESULTADOS}

Os indicadores julgados, ajustados e validados são apresentados integralmente.. A seguir, os resultados da validação realizada.

1 - Julgamento dos construtos operacionais dos indicadores

Este julgamento considerou os itens constitutivos: a fundamentação teórico-científica é suficiente para evidência e apresenta categorias de melhor evidência; o tipo de indicador (estrutura ou resultado) está adequado para a mensuração que se pretende; o numerador e o denominador estão descritos de maneira que não há dúvidas sobre o que se pretende medir; a amostra é adequada para retratar a totalidade da realidade; as fontes de informações são suficientes para avaliar o que se pretende; os critérios para avaliação são claros, objetivos e permitem a mesma interpretação entre avaliadores diferentes, sob as mesmas condições de local e período.

Os resultados são apresentados na Tabela 1, quando se observa que os três indicadores obtiveram consenso favorável para: fundamentação $(100 \%)$, fonte de coleta de dados $(100 \%)$, denominador do indicador $(78 \%)$ e tipo de indicador (variação de $78 \%$ a $89 \%$ ). Para a descrição, somente o indicador 3 obteve consenso favorável $(89 \%)$ e nos critérios para avaliação, somente 
o indicador $2(100 \%)$. Não houve consenso para nenhum dos indicadores, referentes ao numerador (variação de $44 \%$ a $67 \%$ ) e à amostra (variação de $56 \%$ a $67 \%$ ).

Os comentários e sugestões sobre este julgamento são apresentados no Quadro 1 e se referiram, principalmente, às formas de construção e avaliação dos indicadores 1 e 2 , que foram passíveis de ajuste sem necessidade de retorno para outro julgamento.

$\mathrm{Na}$ descrição do indicador 1, as principais questões se referiram à inexistência de protocolos institucionais de indicação e permanência de $\mathrm{CV}$ ou, quando existentes, a discrepância entre eles dificultaria a avaliação. Eles sugeriram incluir as indicações da literatura para $\mathrm{CV}$, que foram acatadas. Mas, nenhuma literatura define um tempo de permanência máximo do CV.

Os principais comentários ao numerador do indicador 1 foram sobre a forma de cálculo. Eles são procedentes e possibilitaram seu ajuste. Um juiz sugeriu avaliar os eventos em vez de pacientes com CV, já que um mesmo paciente pode ser submetido ao CV mais de uma vez durante a internação ou sua avaliação. Outro questionou se haverá somatória da indicação e do tempo de permanência do CV para cálculo do indicador. A intenção original se refere, sim, à somatória de ambos. Mas, conforme necessidade ou interesse, há possibilidade de cálculo isolado. Outra questão disse respeito à forma de registro para se considerar adequada a indicação do CV. Este indicador, entretanto, não se propõe a avaliar se a indicação do $\mathrm{CV}$ e da sua permanência estão adequadas e, sim, se elas estão justificadas. A definição do numerador foi aperfeiçoada, de modo a não permitir esta e outras interpretações.

$\mathrm{Na}$ amostra do indicador 1 os comentários foram sobre a necessidade de definição de locais, tamanho e período. O local e o período dependerão das necessidades da instituição e dos grupos avaliadores. Sugestões para o tamanho foram acrescentadas em anexo, após os manuais operacionais dos indicadores. Outro dado incorporado foi a possibilidade de realizar avaliação prospectiva, retrospectiva e transversal.

A melhor fonte para coleta de informações do indicador 1 é o prontuário, mas houve comentário sobre a necessidade de definir ou selecionar locais de avaliação com probabilidade maior de existência de registro de indicação e de permanência do CV. As autoras, porém, consideram que independente do setor, os registros devem ser sempre realizados da melhor forma possível ou conforme normas da instituição.

Nos critérios para avaliação deste indicador, novamente apareceu a questão da necessidade de se definir indicações adequadas para o $\mathrm{CV}$, que não se referem a esta avaliação. Para excluir esta possibilidade de interpretação ao título do indicador foi acrescentada a palavra registro de indicação e de permanência do
CV.

$\mathrm{Na}$ descrição do indicador 2, além de uma sugestão para melhor detalhá-la, vários comentários (e em outros itens também) se referiram sobre a forma de avaliação da manutenção do CV, ou seja, com ou sem observação dos profissionais nos momentos de realização de cuidados com o CV. Houve, inclusive, um comentário sobre a discordância entre o título do indicador e o que ele avalia, pois o título sugeriria a contemplação da realização das técnicas de cuidados com o CV, que não é confirmada no manual operacional.

A intenção original deste indicador é a análise da qualidade das condições de manutenção do CV e não da observação dos profissionais realizando cuidados. Os autores do estudo consideram que esta forma de avaliação é mais ágil para detectar problemas de manutenção de uma forma geral, como um "recorte" de situação em um dado período de assistência. Já, a observação de profissionais implicaria demanda de tempo muito maior, pois haveria necessidade de "aguardar" os momentos de realização de cuidados ou de manipulação do CV de uma amostra estatisticamente significativa de profissionais e, ainda, com a possibilidade de desvio de desempenho dos mesmos, ao saberem-se observados. Além disto, a avaliação dos componentes de manutenção deste indicador não necessita ser realizada no momento de execução de cuidados com o $\mathrm{CV}$, pois ela compreende averiguar se o sistema está fechado, a fixação adequada, a posição da bolsa coletora abaixo da bexiga e o fluxo urinário desobstruído ${ }^{(4,9)}$.

Está claro, contudo, que esta avaliação permite indiretamente a avaliação da capacidade técnica dos profissionais nos cuidados com $\mathrm{CV}$ e a conclusão pela necessidade ou não de treinamento. $O$ título e a descrição deste indicador 2 foram aperfeiçoados, para não deixar dúvidas sobre o que e como ele avalia.

Em relação ao numerador e denominador do indicador 2, a intenção original é somar o total dos componentes de manutenção de CV adequados em relação à amostra total de $\mathrm{CV}$, considerados na avaliação. Assim, basta um componente não estar adequado para o resultado de um dado CV não obter conformidade. Já, a sugestão para avaliar isoladamente cada componente de manutenção do CV pode ser realizada, pois seus totais isolados são contemplados na planilha de avaliação.

$\mathrm{Na}$ amostra do indicador 2 os comentários dirigiramse, novamente, à avaliação do quadro de profissionais, o que incluiria o momento de realização de procedimentos e, obviamente, a possibilidade de contemplar um mesmo paciente mais de uma vez. Conforme já esclarecido, esta não se refere às observações de profissionais, mas das condições de manutenção do CV. E a definição deste recorte, ou seja, quantos, onde e quando observar dependerá da decisão 
dos avaliadores da instituição, podendo abranger todo o hospital, setores, plantões ou apenas um dado período. Ao se avaliar todos os períodos um mesmo paciente com CV poderá, sim, ser avaliado mais de uma vez. Tais possibilidades foram acrescentadas no manual operacional.

Para o indicador 3, não houve consenso favorável em definição do numerador, amostra e critérios para avaliação. A descrição e o tipo de indicador, apesar de terem obtido consenso favorável, um juiz entendeu que há "mistura" na avaliação de estrutura e processo ao mesmo tempo. A construção original seria uma avaliação de estrutura. Porém, de fato, ele apresenta também avaliações de processo, pela forma como foram construídos os componentes de treinamento e de material para a realização do procedimento de CV. As bases conceituais para construção de indicadores clínicos de avaliação não consideram um mesmo indicador apresentar mais de uma tipologia de avaliação ao mesmo tempo. Então, este indicador 3 deveria ser totalmente reconstruído ou indicadores isolados deveriam ser elaborados para cada um de seus componentes, que são: registro de treinamento de $\mathrm{CV}$; materiais necessários para a realização de $\mathrm{CV}$; itens de um protocolo de CV. Os outros julgamentos, adiante, confirmam o problema de construção deste indicador.

No numerador, houve referência sobre a dificuldade para medir e qualificar os treinamentos apenas com registros de sua realização, sendo necessários outros detalhes como universo e freqüência de pessoal submetido a treinamento, conteúdo e tipo de treinamento, sistema de avaliação entre outros. Sobre a amostra, um juiz comentou que "A falta do material ou a troca da qualidade do material para CV e modificações da qualidade dos treinamentos realizados podem determinar variações no processo sem modificar o indicador". Isto de fato é verdadeiro, porque o indicador se propõe a avaliar apenas a existência de materiais necessários e a realização de treinamento, mas não a qualidade dos mesmos.

No item fontes de informações, foi comentado sobre a subjetividade do protocolo e do registro de treinamento, pois na prática, apesar de excelentes protocolos, eles podem não acatados, bem como é difícil mensurar a efetividade dos treinamentos.

Em critérios para avaliação foram vários os motivos para não consenso, incluindo, novamente, a subjetividade dos protocolos e registros de treinamento.

2) Julgamento dos atributos do conjunto dos indicadores

Os atributos selecionados para julgamento do conjunto dos indicadores foram: acessível - os dados são acessados rapidamente, com mínimo de esforço e custo; comunicável - a relevância da medida pode ser facilmente explicada e compreendida; contextualizável - a medida é obtida livre de contexto ou efeitos do contexto podem ser ajustados; efetivo/preciso - mede o que se propõe medir; exeqüível - a medida é aplicável; objetivo - permite ação de mensuração clara, sem julgamento subjetivo.

Os resultados são apresentados na Tabela 2, onde se verifica que os três indicadores obtiveram consenso favorável em praticamente todos os atributos. A exceção foi o indicador 1, para o atributo acessível.

O Quadro 2 apresenta os comentários e sugestões sobre este julgamento. Com relação ao comentário ao atributo acessível do indicador 1 , foi considerado que o acesso às informações para avaliação depende de como a instituição monitora o CV e favorece a obtenção do prontuário. Esta questão, na verdade, não se refere apenas para prontuários de pacientes submetidos a CV. Mas, se a finalidade principal de avaliação com estes indicadores é a melhoria contínua de qualidade, ela só será realizada sob aprovação da instituição e disposição de seus prontuários. Já, a questão ética ao utilizar prontuários e pacientes para avaliação pode ser contornada pela submissão da avaliação aos comitês de ética e concordância aos termos de compromisso e de consentimento livre e esclarecido. No atributo contextualizável o comentário de um juiz foi realmente procedente, ao se referir à necessidade da qualidade dos registros em prontuário para a aplicação do indicador 1. Os ajustes realizados neste indicador, em Anexo, estabelecem critérios para esta qualificação.

Já, no indicador 3, apesar de consenso favorável em todos os atributos, os comentários apontaram novamente sérios problemas para a avaliação e, assim como no julgamento do manual operacional, houve ênfase na subjetividade da avaliação dos seus componentes.

3) Julgamento dos componentes dos indicadores.

Neste julgamento, os atributos considerados foram: comportamental: avaliação clara e precisa; objetividade: resposta pontual; simplicidade: única idéia, sem outras interpretações; clareza: inteligível, com expressões simples e inequívocas; pertinência: não insinua atributo diferente do definido; precisão: cada componente é distinto dos demais; variedade: termos usados especificam cada item, ou seja, não dão idéia de repetição; credibilidade: não parece descaracterizado ou despropositado em relação ao contínuo do indicador.

A Tabela 3 apresenta os resultados deste julgamento, quando se verifica que houve consenso favorável em quase todos estes atributos nos três indicadores. As exceções foram o atributo simplicidade no indicador 3 e comportamental no indicador 1.

No Quadro 3, sobre os comentários e sugestões dos componentes dos indicadores, nos atributos comportamental e credibilidade do indicador 1 há menção, novamente, às questões sobre definição das indicações 
adequadas para o CV e a dependência da qualidade dos registros para a avaliação com este indicador. Tais questões, já apresentadas no julgamento anterior, foram passíveis de ajustes do manual operacional.

$O$ indicador 3, novamente, recebeu várias considerações dos especialistas. Apesar dos consensos favoráveis nos atributos de seus componentes, exceto no de simplicidade, estas considerações, somadas àquelas apresentadas no julgamento do seu manual operacional, reforçam a impossibilidade de manutenção deste indicador, nesta forma de construção.

4) Valoração da relevância dos componentes do Indicador 3

Neste julgamento, conforme a Tabela 4 , nenhum dos componentes do indicador 3 obteve consenso favorável, porque três juízes, em vez de valorarem cada componente, realizaram uma única valoração para o conjunto dos componentes. Isto ocorreu apesar de uma solicitação clara, no instrumento, para a necessidade de valorar cada componente na própria planilha do indicador. Esta valoração de conjunto, contudo, obteve pontuações 3 ou 4 . Os demais juízes valoraram a maioria dos componentes entre 3 e 4, mas sua somatória não obteve o valor de consenso mínimo de $75 \%$. Caso as valorações de conjunto dos três juízes se confirmassem para cada um dos componentes, todos teriam obtido consenso favorável. Para sua aprovação, o instrumento deveria ser devolvido aos três juízes para a valoração de forma correta, mas os problemas identificados anteriormente, na construção deste indicador, inviabilizaram sua aprovação.

\section{DISCUSSÃO}

A literatura científica é unânime sobre a relação entre a redução do $\mathrm{CV}$ e seu tempo de permanência e a diminuição significativa de incidência e prevalência geral da ITU. Outro fator relacionado é a prática adequada de sua inserção e manutenção.

Algumas situações clínicas que indicam o CV são apresentadas na literatura ${ }^{(4,7,9)}$, e foram incorporadas na descrição do indicador 1, em Anexo. Porém condições clínicas não relacionadas na literatura também podem indicar o CV. Outra questão se refere à duração de sua permanência, cuja literatura nem mesmo apresenta critérios, considerando apenas que deve ser a mais curta possível $^{(4,9)}$.

Tais situações tornam praticamente impossível avaliar sua indicação com critérios pré-estabelecidos para todas as instituições e especialidades. Apesar disto, as autoras deste estudo consideram que esses aspectos necessitam ser avaliados, ainda que indiretamente, de forma a denotar, pelo menos, preocupação profissional e institucional, uma vez que os mesmos são altamente relevantes no CIH. Essa avaliação, mesmo ao se reportar apenas a registros ou acato a protocolos, já configura um grande avanço qualitativo de prática assistencial.

Este estudo evidenciou o desafio de elaborar e validar indicadores clínicos de processo e de estrutura para avaliação de práticas de controle e prevenção de ITU associada a cateter vesical. Este desafio é constatado nas sugestões e comentários efetuados durante os julgamentos, que, inclusive, não possibilitaram validar o indicador 3 , ainda que tenha sido praticamente unânime o reconhecimento, pelos especialistas, de sua importância. Em conseqüência, conclui-se que a relevância de uma dada ação não é condição suficiente para elaborar medidas para sua avaliação, se sua construção não possibilitar a aplicação de maneira objetiva e inequívoca. Contudo, o conteúdo do indicador 3 , dada sua importância para uma avaliação mais completa destas práticas, será re-elaborado e novamente submetido à validação.

Outro desafio deste estudo foi realizar a validação de conteúdo com um método comum na área psicossocial ${ }^{(23,24)}$, porém ainda pouco utilizado em áreas eminentemente técnicas, como a do CIH.

Os indicadores construídos e validados obviamente não esgotam todas as práticas, mas dirigem-se àquelas fundamentais, conforme literatura científica e amplo consenso na prática assistencial, para a prevenção de ITU associada a cateter.

Tais indicadores, porém, ao se somarem a outros em construção, oferecerão condições para o desenvolvimento de uma nova forma de avaliação e acompanhamento da qualidade de práticas gerais de $\mathrm{CIH}$, contribuindo para a formulação de políticas públicas e sistemas de gerenciamento de qualidade pelas próprias instituições de saúde.

Por fim, ainda que validados tais indicadores necessitarão ser ajustados quanto à forma de coleta dos dados e à definição da amostra, por ocasião de sua aplicação, para atender à especificidade assistencial de cada instituição e, desta maneira, garantir a confiabilidade dos resultados.

\section{CONCLUSÃO}

Foram construídos e submetidos à validação de conteúdo três indicadores para a avaliação de práticas de controle de infecção hospitalar do trato urinário associada a cateter vesical, referente a: 1 - Indicação e Permanência do Cateterismo Vesical (IUIC); 2 Manutenção do Cateterismo Vesical (IUMN); 3 - InfraEstrutura para Procedimento de Cateterismo Vesical (IUIF). Na submissão ao processo de validade de conteúdo, somente o indicador 3 não foi aprovado, o 
qual, apesar de ser reconhecida sua importância para o controle e prevenção deste tipo de infecção hospitalar, apresentou problemas de construção para sua aplicação.

Manuais operacionais dos indicadores de avaliação de práticas de controle e prevenção de ITU reajustados após julgamento de validação

Indicador 1: Registro de indicação e permanência do cateterismo vesical (IUIC)

Descrição: o cateterismo vesical (CV) e sua permanência são as principais causas de ITU. Assim, suas limitações são práticas de melhor evidência para a prevenção de ITU. Algumas situações clínicas são relatadas na literatura científica para a indicação do CV: retenção urinária aguda ou crônica; controle do fluxo urinário em cirurgia de grande porte; drenagem pós-operatória; paralisia ou lesão medular; irrigação terapêutica da bexiga; obstrução do trato urinário; drenagem em pacientes com bexiga neurogênica; cirurgias urológicas ou outras cirurgias em estruturas contíguas; medidas acuradas de débito urinário em pacientes críticos $(7,9,25,26)$. No entanto, a variedade de outras situações clínicas, critérios médicos individuais e protocolos institucionais inviabiliza a realização de uma avaliação da adequação da indicação do CV apenas em consonância com a literatura científica; Do mesmo modo, a avaliação de seu tempo de permanência, cujo prazo máximo nem é citado na literatura. Uma possibilidade seria as instituições possuírem protocolos de indicação e permanência de CV adaptados às suas realidades de assistência. $\mathrm{O}$ protocolo, no entanto, não é suficiente para garantir que tais práticas sejam adequadamente realizadas. Uma avaliação eficaz deveria analisar se elas estão de acordo com o protocolo da instituição. Mas, no momento atual, nem todos os hospitais possuem protocolo específico. E, mesmo assim, ainda há a questão da possibilidade de situações clínicas e condutas individuais que extrapolem as normas previamente previstas. Dada a importância destes procedimentos para o $\mathrm{CIH}$, tais dificuldades não podem ser obstáculos para a avaliação de sua adequação ou conformidade. A determinação institucional para que os profissionais ao menos apresentem formalmente (registro em prontuário) suas justificativas para este procedimento e sua manutenção, já seria um grande avanço qualitativo. Tendo em vista esta problemática, este indicador opta, em avaliações iniciais, considerar a existência de registro de justificativa para a realização do $C V$ e a anotação contínua do tempo de permanência. Tal avaliação, se não é ainda o ideal, ao menos constata preocupação profissional e ou institucional com a adequação desta prática.

Fundamentação científica: recomendações de melhor evidência, categoria $A$, em:
- Guideline for Prevention of Catheter-associated Urinary Tract infections. Center for Disease Control and Prevention. 1981.

- Guideline for Preventing Infections associated with the insertion and maintenance of short-term indwelling urethral catheters in acute care. J Hosp Infect. 2001; 47(Suppl): S39-S46.

Tipo de indicador: processo.

Cálculo do indicador:

Total de prontuários de pacientes submetidos a

CV de demora com registro de justificativa para a realização e anotação do tempo de permanência

Total de prontuários de pacientes submetidos a X 100

$\mathrm{CV}$ de demora avaliados

OBS: Se for interesse do grupo avaliador, o cálculo também poderá ser realizado isoladamente, para indicașão ou tempo de permanência

Fonte de informação: prontuários de pacientes submetidos a cateterismo vesical.

Critérios para avaliação: registros médicos ou de enfermagem em prontuários de pacientes submetidos a $\mathrm{CV}$, com anotação contínua de seu tempo de permanência e cuja realização do procedimento está acompanhada de alguma informação que a justifique (Exs: alteração na evolução clínica, preparo para cirurgia, mudança de estratégia de condução do tratamento etc). A adequação a estes critérios é notificada como: A (Atende) - há registros justificando o $\mathrm{CV}$ e o tempo de permanência é registrado continuamente; NA (Não Atende) - qualquer uma das situações acima não é atendida.

Amostra para conformidade: conforme deliberação do grupo avaliador e ou necessidade do serviço, a amostra pode ser prospectiva (prontuários de pacientes em CV no momento de avaliação), retrospectiva (prontuários de pacientes submetidos, anteriormente, a CV) ou ambas ao mesmo tempo. Pode se referir a CV realizado em todo o hospital ou em determinado setor em um dado período de tempo. Sugestões de planos amostrais são apresentadas após os manuais operacionais.

Periodicidade da avaliação: conforme deliberação do grupo avaliador ou sempre que houver algum surto de infecção urinária relacionada com o CV.

Planilha de avaliação do indicador 1

Serviço de saúde:

Setor:

\begin{tabular}{|c|c|c|c|}
\hline \multirow[b]{3}{*}{ Prontuário } & \multicolumn{3}{|c|}{$\begin{array}{l}\text { Fundam. } \\
\text { Categ. A }\end{array}$} \\
\hline & $\begin{array}{l}\text { Indicação da } \\
\text { inserção }\end{array}$ & $\begin{array}{c}\text { Tempo de } \\
\text { permanência }\end{array}$ & Conclusão \\
\hline & $\begin{array}{c}\text { A NA } \\
\text { (Reg Enf e/ou } \\
\text { Médico*) }\end{array}$ & $\begin{array}{c}\text { A } \quad \text { NA } \\
\text { Reg Enf e/ou } \\
\text { Médico*) }\end{array}$ & $\mathrm{A} \mid \mathrm{NA}$ \\
\hline 1 & & & \\
\hline 2 & & & \\
\hline TOTAL & & & \\
\hline
\end{tabular}

* Caso seja de interesse, identificar a fonte de registro

Observações: 
Índice geral de conformidade do indicador:

Total de prontuários de pac. submetidos a CV c/ registro de justificativa para a realização e anotação do tempo de permanência

Total de prontuários de pacientes submetidos a $\mathrm{CV}$ avaliados

Índice de conformidade do registro de justificativa para indicação do CV

Total de prontuários de pacientes submetidos a

$\mathrm{CV}$ c/ registro de justificativa para a realização $\quad \mathrm{X} 100$

Total de prontuários de pacientes submetidos a

CV de avaliados

Índice de conformidade do registro de tempo de Permanência Total de prontuários de pacientes submetidos a $\mathrm{CV}$ c/ registro do tempo de permanência X 100

Total de prontuários avaliados de pacientes submetidos a CV

Indicador 2: Condições de manutenção do cateterismo vesical (IUMN)

Descrição: várias condições para a manutenção adequada do cateterismo vesical (CV) são encontradas na literatura científica ${ }^{(9,21,22)}$. Aquelas com melhor categoria de fundamentação constituem os componentes sob avaliação deste indicador e correspondem a: sistema de drenagem fechado; fixação adequada do cateter; posicionamento da bolsa coletora abaixo do nível da bexiga; fluxo urinário desobstruído. Este indicador avalia, prospectivamente, as condições de manutenção do CV nos pacientes internados e, em decorrência, a qualidade do preparo técnico dos profissionais.

Fundamentação científica: os componentes sob avaliação têm evidências de categoria $\mathrm{A}$, baseadas em:

- Guideline for Prevention of Catheter-associated Urinary Tract infections. Center for Disease Control and Prevention. 1981.

- Guideline for Preventing Infections associated with the insertion and maintenance of short-term indwelling urethral catheters in acute care. J Hosp Infect 2001; 47 (Suppl):S39-S46.

- Mangini C (coordenador). Prevenção de infecção do trato urinário hospitalar. São Paulo: Associação Paulista de Estudos e Controle de Infecção Hospitalar. 2000.

Tipo de indicador: processo.

Cálculo do indicador:

Total de CV com todos os componentes de manutenção adequados X 100

Total de avaliações de CV em pacientes internados

OBS: A planilha construida para a avaliação permite também o cálculo de conformidade para cada componente de manutenção do CV.

Fonte de informação: observação direta (OD) de pacientes com cateterismo vesical.

Critérios para qualificação: observação direta de pacientes com CV, considerando: A (Atende) - a) o sistema de drenagem está fechado e b) a fixação do cateter está adequada (homem: hipogástrio; mulher: face interna da raiz da coxa) e c) a bolsa coletora encontra-se abaixo do nível da bexiga e d) o fluxo urinário está desobstruído. NA (Não Atende) - não conformidade de qualquer uma das condições acima citadas.

$O B S$ : para melhor avaliação, os $C V$ devem ser observados em um mesmo momento previamente definido. Se for durante a realização de cuidados, épreciso ter em mente que o profissional, se souber que está sendo observado, pode alterar sua forma cotidiana de trabalhar. A avaliação de cada turno de trabalho pode ser realizada após a troca de plantão e realização dos primeiros cuidados com o paciente.

Amostra para análise de conformidade: de acordo com as necessidades do grupo avaliador ou da instituição, a amostra poderá englobar um ou todos os turnos (manhã, tarde e noite) e alguns setores específicos ou todo o hospital. Uma amostra representativa para conformidade pode ser obtida em setores com maior volume de pacientes com cateterismo com mais de um dia de permanência, como a UTI. Sugestões para amostra são apresentadas no final deste manual.

Periodicidade da avaliação: conforme deliberação do grupo avaliador ou sempre que houver algum surto de infecção urinária relacionada com o cateterismo vesical.

Planilha para avaliação:

\section{Serviço de saúde:}

Setor:

\begin{tabular}{|c|c|c|c|c|c|}
\multicolumn{2}{c}{ Cat. A } & \multicolumn{1}{c}{ Cat. A } & \multicolumn{2}{c|}{ Cat. A } & \multicolumn{2}{c|}{ Cat. A } & \\
\hline & $\begin{array}{c}\text { Sist } \\
\text { Fech. } \\
\text { A NA }\end{array}$ & $\begin{array}{c}\text { Fixaçã } \\
\text { o Adeq } \\
\text { A NA }\end{array}$ & $\begin{array}{c}\text { Bolsa abx } \\
\text { da bexiga } \\
\text { A NA }\end{array}$ & $\begin{array}{c}\text { Flx urinário } \\
\text { desobstruído } \\
\text { A NA }\end{array}$ & Concl* \\
\hline 1 & & & & & \\
\hline 2 & & & & & \\
\hline T & & & & & \\
\hline
\end{tabular}

* $A$ conclusão é $A$ quando todos os componentes de cada CV avaliado forem atendidos. A conclusão é NA quando qualquer um dos componentes de cada $C V$ avaliado não for atendido.

Observações:

Índice de conformidade geral do indicador:

Total de CV com todos os componentes de X 100 manutenção adequados

Total de CV de demora avaliados

Índice de conformidade do sistema de drenagem

Total de CV de demora com drenagem fechada $\quad$ X 100

Total de CV de demora avaliados

Índice de conformidade da fixação adequada

Total de CV de demora com fixação adequada

Total de CV de demora avaliados

Índice de conformidade do posicionamento da bolsa coletora abaixo da bexiga

Total de CV de demora com bolsa coletora abaixo X 100 da bexiga

Total de CV de demora avaliados 
Índice de conformidade do fluxo urinário desobstruído Total de CV de demora com fluxo desobstruído X 100

Total de CV de demora avaliados

\section{REFERÊNCIAS}

1. Gagliardi EMDB, Fernandes AT, Cavalcante NJF. Infecção do trato urinário. In: Fernandes AT, editor. Infecção hospitalar e suas interfaces na área da saúde. São Paulo: Atheneu; 2000. v. 1. cap. 18. p. 459-78.

2. Rodrigues EAC. Infecções hospitalares: prevenção e controle. São Paulo: Sarvier; 1997. cap.1, p. 135-67.

3. Turrini RNT. Infecção do trato urinário. In: Lacerda RA. Controle de infecção em centro cirúrgico: fatos, mitos e controvérsias. São Paulo: Atheneu; 2003. cap. 7. p. 103-15.

4. Center for Disease Control and Prevention (CDC). Guideline for prevention of catheter-associated urinary tract infections, EUA,1981. [text on the Internet]. [cited 2001 Nov 24]. Available from: http://www.cdc.gv/ncidod/hip/guide/ uritract.htm>

5. Keerasuntonpong A, Thearawiboon W, Panthawanan A, Judaeng T, Kachintorn K, Jintanotaitatavorn D, et al. Incidence of urinary tract infections in patients with shortterm indwelling urethral catheters: a comparison between a 3-day urinary drainage bag change and no change regimens. Am J Infect Control. 2003; 31(1):9-12.

6. Hokama CSM, Vattimo MFF. Cateterismo vesical. In: Lacerda RA. Controle de Infecção em centro cirúrgico: fatos, mitos e controvérsias. São Paulo: Atheneu; 2003. cap. 26. p. 425-37.

7. Mangini C (coordenador). Prevenção de infecção do trato urinário hospitalar. São Paulo: Associação Paulista de Estudos e Controle de Infecção Hospitalar; 2000.

8. Emori TG, Banerjee SN, Culver DH, Gaynes RP, Horan TC, Edwards JR, et al. Nosocomial infections in elderly patients in the United States, 1986-1990. National Nosocomial Infections Surveillance System. Am J Med. 1991; 91(3B):289S-293S.

9. Panknin HT, Althaus P. Guidelines for preventing infections associated with the insertion and maintenance of shortterm indwelling urethral catheters in acute care. J Hosp Infect 2001; 49(2):146-7.

10. Pringle M, Wilson T, Grol R. Measuring "goodness" in individuals and healthcare systems. BMJ. 2002; 325(7366):704-7.

11. Tanaka OY, Melo CMM. Avaliação de programas de saúde do adolescente: um modo de fazer. São Paulo: EDUSP; 2001.

12. Ferreira DP. Indicadores de saúde: construção e uso. In:
Cianciarullo TI, Cornetta VK. Saúde, desenvolvimento: um desafio para os gestores do Terceiro Milênio. São Paulo: Ícone; 2000. p. 259-70.

13. Donaldson MS, editor. The National Roundtable on Health Care Quality, Institute of Medicine. Measuring the quality of health care. Washington: National Academies Press; 1999. http://www.nap.edu/catalog/6418.html

14. McGlynn EA, Asch SM. Developing a clinical performance measure. Am J Prev Med. 1998; 14(3Suppl):14-21.

15. Campbell SM, Braspenning J, Hutchinson A, Marshall MN. Research methods used in developing and applying quality indicators in primary care. BMJ. 2003; 326(7393):816-9.

16. Rawlins M, Hine DD. Principles for best practice in clinical audit. National Institute for Clinical Excellence. Oxon: Radclliffe Medical Press; 2002.

17. An approach to the evaluation of quality indicators of the outcome of care in hospitalized patients, with a focus on nosocomial infection indicators. The Quality Indicator Study Group. Infect Control Hosp Epidemiol. 1995; 16(5):30816. Review.

18. Ovretveit J, Gustafson D. Using research to inform quality programmes. BMJ. 2003; 326(7392):759-61.

19. Atkins D, Best D, Briss PA, Eccles M, Falck-Ytter Y, Flottorp S, Guyatt GH, Harbour RT, Haugh MC, Henry D, Hill S, Jaeschke R, Leng G, Liberati A, Magrini N, Mason J, Middleton P, Mrukowicz J, O'Connell D, Oxman AD, Phillips B, Schunemann HJ, Edejer TT, Varonen H, Vist GE, Williams JW Jr, Zaza S; GRADE Working Group. Grading quality of evidence and strength of recommendations. BMJ. 2004;328(7454):1490.

20. Polit DF, Beck CT, Hungler BP. Fundamentos de pesquisa em enfermagem: métodos, avaliação e utilização. 5a ed. Porto Alegre: Artmed; 2004. cap. 9, p. 199-219.

21. Lynn MR. Determination and quantification of content validity. Nurs Res. 1986; 35(6):382-5.

22. Salmond SW. Orthopaedic nursing research priorities: a Delphi study. Orthop Nurs. 1994; 13(2):31-45.

23. Moron MAM. Concepção, desenvolvimento e validação de instrumentos de coleta de dados para estudar a percepção do processo decisório e as diferenças culturais. [Tese]. Porto Alegre: Escola de Administração da Universidade Federal do Rio Grande do Sul; 1998.

24. Perroca MG. Sistema de classificação de pacientes: construção e validação de um instrumento [tese]. São Paulo: Escola de Enfermagem da Universidade de São Paulo; 1996.

25. Warren JW. Catheter-associated urinary tract infections. Infect Dis Clin North Am. 1997; 11(3):609-22.

26. Kunin CM, McCormack RC. Prevention of catheter-induced urinary-tract infections by sterile closed drainage. N Engl J Med. 1966; 274(21):1155-61. 
Tabela 1 - Consenso de julgamento pelo especialistas dos itens dos Manuais Operacionais dos Indicadores de Avaliação de Controle e prevenção de ITU Associada a Cateter. São Paulo, 2005.

\begin{tabular}{|c|c|c|c|c|c|c|}
\hline \multirow{2}{*}{$\begin{array}{l}\text { INDICADOR } \\
\text { ITENS DO MANUAL } \\
\text { Descrição }\end{array}$} & \multicolumn{2}{|c|}{$\begin{array}{l}\text { Indicação e permanência } \\
\text { do Cateterismo (IUIC) } \\
\text { Indicador } 1\end{array}$} & \multicolumn{2}{|c|}{$\begin{array}{l}\text { Manutenção do cateter } \\
\text { vesical (IUMN) } \\
\text { Indicador } 2\end{array}$} & \multicolumn{2}{|c|}{$\begin{array}{l}\text { Infra-estrutura para procedimentos } \\
\text { com cateterismo vesical (IUIF) } \\
\text { Indicador } 3\end{array}$} \\
\hline & $\mathrm{n}$ & $\%$ & n & $\%$ & $\mathrm{n}$ & $\%$ \\
\hline Sim & 6 & 67 & 6 & 67 & 8 & 89 \\
\hline Não & 3 & 33 & 3 & 33 & 1 & 11 \\
\hline Não respondeu & - & - & - & - & - & - \\
\hline Não se aplica & - & - & - & - & - & - \\
\hline Total & 9 & 100 & 9 & 100 & 9 & 100 \\
\hline Fundamentação & $\mathrm{n}$ & $\%$ & n & $\%$ & $n$ & $\%$ \\
\hline Sim & 9 & 100 & 9 & 100 & 9 & 100 \\
\hline Não & - & - & - & - & - & - \\
\hline Não respondeu & - & - & - & - & - & - \\
\hline Não se aplica & - & - & - & - & - & - \\
\hline Total & 9 & 100 & 9 & 100 & 9 & 100 \\
\hline Tipo de Indicador & $\mathrm{n}$ & $\%$ & n & $\%$ & $\mathrm{n}$ & $\%$ \\
\hline $\operatorname{Sim}$ & 8 & 89 & 7 & 78 & 7 & 78 \\
\hline Não & 1 & 11 & 2 & 22 & 2 & 22 \\
\hline Não respondeu & - & - & - & - & - & - \\
\hline Não se aplica & - & - & - & - & - & - \\
\hline Total & 9 & 100 & 9 & 100 & 9 & 100 \\
\hline Numerador & $\mathrm{n}$ & $\%$ & n & $\%$ & $\mathbf{n}$ & $\%$ \\
\hline Sim & 5 & 56 & 4 & 44 & 6 & 67 \\
\hline Não & 4 & 44 & 5 & 56 & 3 & 33 \\
\hline Não respondeu & - & - & - & - & - & - \\
\hline Não se aplica & - & - & - & - & - & - \\
\hline Total & 9 & 100 & 9 & 100 & 9 & 100 \\
\hline Denominador & $\mathrm{n}$ & $\%$ & $\mathrm{n}$ & $\%$ & $n$ & $\%$ \\
\hline $\operatorname{Sim}$ & 7 & 78 & 7 & 78 & 7 & 78 \\
\hline Não & 2 & 22 & 2 & 22 & 2 & 22 \\
\hline Não respondeu & - & - & - & - & - & - \\
\hline Não se aplica & - & - & - & - & - & - \\
\hline Total & 9 & 100 & 9 & 100 & 9 & 100 \\
\hline Amostra & $\mathrm{n}$ & $\%$ & n & $\%$ & $\mathrm{n}$ & $\%$ \\
\hline Sim & 6 & 67 & 5 & 56 & 5 & 56 \\
\hline Não & 1 & 11 & 2 & 22 & - & - \\
\hline Não respondeu & 1 & 11 & 1 & 11 & 2 & 22 \\
\hline Não se aplica & 1 & 11 & 1 & 11 & 2 & 22 \\
\hline Total & 9 & 100 & 9 & 100 & 9 & 100 \\
\hline Fontes de coleta de informações & $\mathrm{n}$ & $\%$ & n & $\%$ & $\mathbf{n}$ & $\%$ \\
\hline Sim & 9 & 100 & 9 & 100 & 9 & 100 \\
\hline Não & - & - & - & - & - & - \\
\hline Não respondeu & - & - & - & - & - & - \\
\hline Não se aplica & - & - & - & - & - & - \\
\hline Total & 9 & 100 & 9 & 100 & 9 & 100 \\
\hline Critérios para avaliação & $\mathbf{n}$ & $\%$ & n & $\%$ & $\mathrm{n}$ & $\%$ \\
\hline $\operatorname{Sim}$ & 6 & 67 & 9 & 100 & 6 & 67 \\
\hline Não & 2 & 22 & - & - & 2 & 22 \\
\hline Não respondeu & 1 & 11 & - & - & 1 & 11 \\
\hline Não se aplica & - & - & - & - & - & - \\
\hline Total & 9 & 100 & 9 & 100 & 9 & 100 \\
\hline
\end{tabular}


Quadro 1 - Comentários e sugestões dos especialistas no julgamento dos Manuais Operacionais dos Indicadores de Avaliação de Controle e prevenção de ITU Associada ao Cateter. São Paulo, 2005.

\begin{tabular}{|c|c|c|}
\hline 1- Indicação e Permanência do cateter vesical (IUIC) & 2- Manutenção do cateter Vesical (IUMN) & $\begin{array}{l}\text { 3- Infra-estrutura para } \\
\text { procedimento com } \\
\text { cateterismo (IUIF) }\end{array}$ \\
\hline \multicolumn{3}{|c|}{ Descrição } \\
\hline $\begin{array}{l}\text { 1) O CV é um dos principais fatores de risco para ITU, no } \\
\text { entanto há discrepância entre os protocolos institucionais. } \\
\text { 2) Quais são as indicações de CV relatadas na literatura e os } \\
\text { riscos de ITU com o aumento de tempo de permanência? } \\
\text { Ausência de protocolos institucionais (baseados em } \\
\text { pesquisa)? Os hospitais devem ter protocolos, mas segui-los } \\
\text { é outra questão, devido ao problema de pesquisa e da } \\
\text { avaliação do indicador. } \\
\text { 3) A necessidade de "informação mínima" precisa ser } \\
\text { enfatizada, para aumentar a compreensão do texto, ou seja, } \\
\text { antes de avaliar outros critérios precisamos saber se há } \\
\text { documentação... }\end{array}$ & $\begin{array}{l}\text { 1) O título sugere que o indicador } \\
\text { contempla a técnica na manutenção, o que } \\
\text { não se confirma no manual operacional. } \\
\text { 2) A descrição mais detalhada pode } \\
\text { facilitar a compreensão. }\end{array}$ & $\begin{array}{l}\text { Separar melhor os conceitos de } \\
\text { estruturas e processo. }\end{array}$ \\
\hline \multicolumn{3}{|c|}{ Fundamentação científica } \\
\hline Sem comentários e sugestões. & Sem comentários e sugestões. & Sem comentários e sugestões. \\
\hline \multicolumn{3}{|c|}{ Tipo de indicador } \\
\hline $\begin{array}{l}\text { 1) Deveria verificar a adequação da indicação/ tempo de } \\
\text { permanência e não somente registro. } \\
\text { 2) O Indicador poderá refletir mais a qualidade de anotação } \\
\text { médica e de enfermagem no prontuário do que realmente } \\
\text { pretende medir, que é a correta indicação de passagem e } \\
\text { manutenção da SVD. Poderá ocorrer, o que não acontece, de } \\
\text { haver uma indicação formal para o procedimento, mas isso } \\
\text { não está anotado no prontuário. Como o levantamento será } \\
\text { realizado retrospectivamente, será computado como não } \\
\text { adequado, resultando em informação falso-negativa. } \\
\text { Acontecerá também, com alguma freqüência, de haver } \\
\text { descrição de passagem do cateter, mas sem anotação de sua } \\
\text { retirada, não podendo atender a descrição do tempo de } \\
\text { sondagem e de sua conseqüente validade para o estudo. }\end{array}$ & $\begin{array}{l}\text { 2) Descrever o procedimento, estabelecer } \\
\text { método de avaliação do impacto do } \\
\text { treinamento sobre este indicador. } \\
\text { 2) Incluir técnica de manutenção. }\end{array}$ & $\begin{array}{l}\text { 1) Mistura de processo com } \\
\text { estrutura. }\end{array}$ \\
\hline \multicolumn{3}{|c|}{ Descrição do numerador } \\
\hline $\begin{array}{l}\text { 1) O numerador deve ser o número de CV e não de } \\
\text { prontuários, já que o paciente pode ter sido submetido a } \\
\text { mais de um CV. } \\
\text { 2) Registro de seu tempo de permanência e da justificativa. } \\
\text { Enfatizar o desejo de somar. } \\
\text { 3) Elencar os indicadores formais de adequação de } \\
\text { procedimentos. } \\
\text { 4) Desde que sejam melhor descritos, os critérios são } \\
\text { considerados válidos para a passagem e manutenção da } \\
\text { sondagem. } \\
\text { 5) Para o numerador "em que há registro de sua indicação" } \\
\text { não ficou claro se o avaliador deve procurar no prontuário o } \\
\text { registro "indico sondagem devido a..." ou se basta registro de } \\
\text { situação do paciente para que a opinião do avaliador } \\
\text { justifique essa sondagem }\end{array}$ & $\begin{array}{l}\text { 1) Total de itens de manutenção de CV } \\
\text { avaliados como adequados em dado } \\
\text { período de avaliação. } \\
\text { 2) Alguns itens colocados como nível de } \\
\text { evidência A serão difíceis de assegurar se } \\
\text { realmente são respeitados, mesmo que } \\
\text { exista padronização. } \\
\text { 3) Seria melhor especificar cada indicador } \\
\text { isoladamente. Ex: total de catéteres com } \\
\text { sistema fechado; total de catéteres } \\
\text { observados. } \\
\text { 4) Incluir técnica de manutenção. }\end{array}$ & $\begin{array}{l}\text { 1) Dificuldade para medir os } \\
\text { treinamentos realizados. } \\
\text { 2) Referir a total de itens de infra- } \\
\text { estrutura para CV avaliados como } \\
\text { adequados. }\end{array}$ \\
\hline \multicolumn{3}{|c|}{ Descrição do denominador } \\
\hline $\begin{array}{l}\text { 1) O denominador deve ser o número total de } \mathrm{CV} \text { avaliados. } \\
\text { 2) Número total de prontuários de pacientes ...: pode haver } \\
\text { paciente } \mathrm{c} / \text { cateter urinário } \mathrm{s} \text { / registro no prontuário. }\end{array}$ & $\begin{array}{l}\text { 1) Total de itens de manutenção de CV } \\
\text { avaliados como adequados e inadequados. }\end{array}$ & $\begin{array}{l}\text { 1) Em relação aos treinamentos, } \\
\text { quem será o total? } \\
\text { 2) Total de itens de infra- } \\
\text { estrutura para procedimentos de } \\
\text { CV avaliados. }\end{array}$ \\
\hline
\end{tabular}




\begin{tabular}{|c|c|c|}
\hline \multicolumn{3}{|c|}{ Amostra } \\
\hline $\begin{array}{l}\text { 1) Não há definição da amostra no manual operacional. Fica } \\
\text { a critério do grupo? } \\
\text { 2) É necessário estudar o tamanho da amostra para avaliar o } \\
\text { impacto de treinamento/inerente a este processo. } \\
\text { 3) Talvez coletar em UTI seja mais representativo. } \\
\text { 4) Há necessidade de definir o tempo de análise, o total de } \\
\text { procedimento, para definir a amostra. }\end{array}$ & $\begin{array}{l}\text { 1) Pertinente avaliar o quadro de } \\
\text { profissionais e a qualidade do material } \\
\text { usado. } \\
\text { 2) No caso de permanecer na mesma } \\
\text { unidade, levaria o observador a contar o } \\
\text { mesmo cateter no mesmo dia. Talvez fosse } \\
\text { melhor mudar de unidade. }\end{array}$ & $\begin{array}{l}\text { 1) A falta do material ou troca da } \\
\text { qualidade do material e } \\
\text { modificações da qualidade dos } \\
\text { treinamentos realizados podem } \\
\text { determinar variações no processo } \\
\text { sem modificar o indicador. }\end{array}$ \\
\hline \multicolumn{3}{|c|}{ Fontes de coleta de informações } \\
\hline $\begin{array}{l}\text { 1) Local da coleta não foi definido. Caso seja UTI, teremos } \\
\text { grande número de pacientes com SVD e com indicação e } \\
\text { permanência possivelmente descritos e corretos. Em clínicas } \\
\text { médicas e cirúrgicas, nem sempre estas anotações existem. } \\
\text { 2) A fonte (prontuário) é adequada no HU, pois é um } \\
\text { hospital escola, porém se sabeque o registro farto em } \\
\text { prontuário não é a realidade da maioria dos hospitais. } \\
\text { 3) Excelente, no entanto me preocupo com a fonte da coleta } \\
\text { de dados, pois na prática diária, temos grande dificuldade, } \\
\text { pois nem sempre encontramos este registro. Seria necessário } \\
\text { um trabalho educativo prévio. }\end{array}$ & Sem comentários. & $\begin{array}{l}\text { 1) Protocolo e registro de } \\
\text { treinamentos são algo subjetivo, } \\
\text { pois na prática sabemos que } \\
\text { apesar de excelentes protocolos, } \\
\text { os mesmos algumas vezes não são } \\
\text { seguidos, bem como é difícil } \\
\text { mensurar a eficácia dos } \\
\text { treinamentos. Apesar disto, acho } \\
\text { viável a aplicação desse indicador } \\
\text { em associação com os demais, } \\
\text { para uma melhor eficácia. }\end{array}$ \\
\hline \multicolumn{3}{|c|}{ Critérios para avaliação } \\
\hline $\begin{array}{l}\text { 1) Sim, se for para avaliar registro de } \\
\text { indicação/permanência. Não, se for para avaliar adequação } \\
\text { da indicação/permanência. } \\
\text { 2) Estabelecer item a item os critérios considerados válidos } \\
\text { para sondagem vesical. } \\
\text { 3) Definir os critérios para realização do procedimento, que } \\
\text { julgo ser crucial para avaliação correta do indicador em } \\
\text { questão. }\end{array}$ & Sem comentários e sugestões. & $\begin{array}{l}\text { 1) A disponibilidade de material } \\
\text { de boa qualidade e os } \\
\text { treinamentos realizados podem } \\
\text { gerar interpretações variadas. } \\
\text { 2) Protocolo e registro de } \\
\text { treinamentos são algo subjetivo, } \\
\text { pois na prática sabemos que } \\
\text { apesar de excelentes protocolos, } \\
\text { os mesmos algumas vezes não são } \\
\text { seguidos, bem como é difícil } \\
\text { mensurar a eficácia dos } \\
\text { treinamentos. Apesar do descrito } \\
\text { anteriormente, acho viável a } \\
\text { aplicação desse indicador em } \\
\text { associação com os demais, para } \\
\text { uma melhor eficácia. } \\
\text { 3) Especificar quais materiais } \\
\text { devem ser estéreis. }\end{array}$ \\
\hline
\end{tabular}


Tabela 2 - Consenso da Validação do Conjunto de Componentes dos Indicadores de Avaliação de Controle e Prevenção de ITU Associada a Cateter pelos especialistas, segundo seus atributos. São Paulo, 2005.

\begin{tabular}{|c|c|c|c|c|c|c|}
\hline \multirow{2}{*}{$\begin{array}{l}\text { INDICADOR } \\
\text { ATRIBUTO } \\
\text { Atribuível }\end{array}$} & \multicolumn{2}{|c|}{$\begin{array}{l}\text { 1- Indicação e permanência do } \\
\text { Cateterismo (IUIC) }\end{array}$} & \multicolumn{2}{|c|}{$\begin{array}{l}\text { 2- Manutenção do cateter } \\
\text { Vesical (IUMN) }\end{array}$} & \multicolumn{2}{|c|}{$\begin{array}{l}\text { 3- Infra-estrutura para } \\
\text { procedimentos c/ Cateterismo } \\
\text { Vesical (IUIF) }\end{array}$} \\
\hline & $\mathrm{n}$ & $\%$ & $\mathrm{n}$ & $\%$ & $\mathrm{n}$ & $\%$ \\
\hline Não respondeu & - & - & - & - & - & - \\
\hline 1 & 1 & 11 & - & - & 1 & 11 \\
\hline 2 & 1 & 11 & - & - & - & - \\
\hline 3 & 2 & 22 & 2 & 22 & 1 & 11 \\
\hline 4 & 5 & 56 & 7 & 78 & 7 & 78 \\
\hline Total & 9 & 100 & 9 & 100 & 9 & 100 \\
\hline Acessível & $\mathbf{n}$ & $\%$ & $\mathrm{n}$ & $\%$ & $\mathbf{N}$ & $\%$ \\
\hline Não respondeu & 1 & 11 & - & - & - & - \\
\hline $\mathrm{T}_{\mathrm{T}}$ & 1 & 11 & 2 & 22 & 2 & 22 \\
\hline 2 & 1 & 11 & - & - & - & - \\
\hline 3 & 2 & 22 & 7 & 78 & 5 & 56 \\
\hline 4 & 4 & 44 & - & - & 2 & 22 \\
\hline Total & 9 & 100 & 9 & 100 & 9 & 100 \\
\hline Comunicável & $\mathbf{n}$ & $\%$ & $\mathrm{n}$ & $\%$ & $\mathbf{N}$ & $\%$ \\
\hline Não respondeu & - & - & - & - & - & - \\
\hline 1 & - & - & - & - & - & - \\
\hline 2 & - & - & - & - & 1 & 11 \\
\hline 3 & 1 & 11 & - & - & 1 & 11 \\
\hline 4 & 8 & 89 & 9 & 100 & 7 & 78 \\
\hline Total & 9 & 100 & 9 & 100 & 9 & 100 \\
\hline Contextualizável & $\mathbf{N}$ & $\%$ & $\mathrm{n}$ & $\%$ & $\mathbf{n}$ & $\%$ \\
\hline Não respondeu & - & - & - & 1 & 1 & 11 \\
\hline 1 & - & - & - & - & - & - \\
\hline 2 & 1 & 11 & - & - & - & - \\
\hline 3 & 3 & 33 & 1 & 11 & 2 & 22 \\
\hline 4 & 5 & 56 & 8 & 89 & 6 & 67 \\
\hline Total & 9 & 100 & 9 & 100 & 9 & 100 \\
\hline Efetivo/Preciso & $\mathbf{N}$ & $\%$ & $\mathbf{n}$ & $\%$ & $\mathbf{N}$ & $\%$ \\
\hline Não respondeu & - & - & - & - & - & - \\
\hline 1 & - & - & - & - & 1 & 11 \\
\hline 2 & 1 & 11 & - & - & - & - \\
\hline 3 & 1 & 11 & 2 & 22 & 2 & 22 \\
\hline 4 & 7 & 78 & 7 & 78 & 6 & 67 \\
\hline Total & 9 & 100 & 9 & 100 & 9 & 100 \\
\hline Exeqüível & $\mathbf{n}$ & $\%$ & $\mathrm{n}$ & $\%$ & $\mathbf{N}$ & $\%$ \\
\hline Não respondeu & - & - & - & - & - & - \\
\hline 1 & - & - & - & - & - & - \\
\hline 2 & - & - & - & - & - & - \\
\hline 3 & 2 & 22 & 1 & 11 & 3 & 33 \\
\hline 4 & 7 & 78 & 8 & 89 & 6 & 67 \\
\hline Total & 9 & 100 & 9 & 100 & 9 & 100 \\
\hline Objetivo & $\mathbf{N}$ & $\%$ & $\mathrm{n}$ & $\%$ & $\mathbf{n}$ & $\%$ \\
\hline Não respondeu & - & - & - & - & - & - \\
\hline 1 & - & - & - & - & - & - \\
\hline 2 & 2 & 22 & 1 & 11 & - & - \\
\hline 3 & 3 & 33 & 1 & 11 & 4 & 44 \\
\hline 4 & 4 & 44 & 7 & 78 & 5 & 55 \\
\hline Total & 9 & 100 & 9 & 100 & 9 & 100 \\
\hline
\end{tabular}


Quadro 2 - Comentários e sugestões dos especialistas no julgamento dos atributos do conjunto dos Indicadores de Avaliação de Controle e Prevenção de ITU Associada ao Cateter. São Paulo, 2005.

\begin{tabular}{|l|l|l|l|}
\hline $\begin{array}{l}\text { INDICADOR } \\
\text { ATRIBUTOS }\end{array}$ & $\begin{array}{l}\text { 1-Indicação e } \\
\text { Permanência (IUIC) }\end{array}$ & $\begin{array}{l}\text { 2- Manutenção do cateter } \\
\text { Vesical (IUMN) }\end{array}$ & 3- Infra-estrutura para procedimento de CV (IUIF) \\
\hline Atribuível & Sem comentários. & Sem comentários. & Sem comentários. \\
\hline Acessível & $\begin{array}{l}\text { 1) Depende de como a } \\
\text { instituição monitora } \\
\text { os CV. } \\
\text { 2) A acessibilidade } \\
\text { depende da facilidade } \\
\text { de obtenção do } \\
\text { prontuário. }\end{array}$ & Sem comentários. & Depende da organização da instituição. \\
\hline Comunicável & Sem comentários. & Sem comentários. & Sem comentários. \\
\hline Contextualizável & $\begin{array}{l}\text { Qualidade dos } \\
\text { registros em } \\
\text { prontuários médicos. }\end{array}$ & Sem comentários. & Sem comentários. \\
\hline Efetiva/ precisa & Sem comentários. & Sem comentários. & $\begin{array}{l}\text { Protocolo e registro de treinamentos são subjetivos, } \\
\text { pois na prática sabemos que apesar de excelentes } \\
\text { protocolos, os mesmos algumas vezes não são } \\
\text { seguidos, bem como é difícil mensurar a eficácia } \\
\text { dos treinamentos. Apesar do descrito anteriormente, } \\
\text { acho viável a aplicação desse indicador em } \\
\text { associação com os demais, para uma melhor eficácia. }\end{array}$ \\
\hline Exeqüível & Sem comentários. & $\begin{array}{l}\text { Embora extremamente } \\
\text { trabalhosa. }\end{array}$ & $\begin{array}{l}\text { Para alguns itens acho difícil mensurar. Ex. lavagem } \\
\text { das mãos antes e depois de procedimento. }\end{array}$ \\
\hline Objetiva & Sem comentários. & Sem comentários. & Sem comentários. \\
\hline
\end{tabular}

Tabela 3 - Consenso de Validação dos Componentes dos Indicadores de Avaliação de Controle e Prevenção de ITU Associada a Cateter Vesical. São Paulo, 2005

\begin{tabular}{|c|c|c|c|c|c|c|}
\hline $\begin{array}{l}\text { INDICADOR } \\
\text { ATRIBUTO }\end{array}$ & $\begin{array}{l}\text { 1-Indica } \\
\text { Cateteris }\end{array}$ & $\begin{array}{l}\text { manência } \\
\text { C) }\end{array}$ & $\begin{array}{l}\text { 2- Manu } \\
\text { Vesical }\end{array}$ & cateter & $\begin{array}{l}\text { 3- Infra- } \\
\text { procedin } \\
\text { Cateteris }\end{array}$ & \\
\hline Comportamental & $\mathbf{n}$ & $\%$ & n & $\%$ & $\mathbf{n}$ & $\%$ \\
\hline $\operatorname{Sim}$ & 06 & 67 & 08 & 89 & 07 & 78 \\
\hline Não & 03 & 33 & 01 & 11 & 02 & 22 \\
\hline Não respondeu & 00 & 00 & 00 & 00 & 00 & 00 \\
\hline Total & 09 & 100 & 09 & 100 & 09 & 100 \\
\hline Objetividade & $\mathbf{n}$ & $\%$ & $\mathrm{n}$ & $\%$ & $\mathrm{n}$ & $\%$ \\
\hline Sim & 08 & 89 & 09 & 100 & 08 & 89 \\
\hline Não & 01 & 11 & 00 & 00 & 01 & 11 \\
\hline Não respondeu & 00 & 00 & 00 & 00 & 00 & 00 \\
\hline Total & 09 & 100 & 09 & 100 & 09 & 100 \\
\hline Simplicidade & $\mathrm{n}$ & $\%$ & $\mathbf{n}$ & $\%$ & $\mathrm{n}$ & $\%$ \\
\hline Sim & 08 & 89 & 09 & 100 & 06 & 67 \\
\hline Não & 01 & 11 & 00 & 00 & 03 & 33 \\
\hline Não respondeu & 00 & 00 & 00 & 00 & 00 & 00 \\
\hline Total & 09 & 100 & 09 & 100 & 09 & 100 \\
\hline Clareza & $\mathbf{n}$ & $\%$ & n & $\%$ & $\mathbf{n}$ & $\%$ \\
\hline Sim & 08 & 89 & 09 & 100 & 08 & 89 \\
\hline Não & 00 & 00 & 00 & 00 & 01 & 11 \\
\hline Não respondeu & 01 & 11 & 00 & 00 & 00 & 00 \\
\hline Total & 09 & 100 & 09 & 100 & 09 & 100 \\
\hline $\begin{array}{l}\text { Pertinência, saturação ou corres- } \\
\text { pondência }\end{array}$ & $\mathrm{n}$ & $\%$ & $\mathbf{n}$ & $\%$ & $\mathbf{n}$ & $\%$ \\
\hline Sim & 08 & 89 & 08 & 89 & 08 & 89 \\
\hline Não & 00 & 00 & 00 & 00 & 00 & 00 \\
\hline Não respondeu & 01 & 11 & 01 & 11 & 01 & 11 \\
\hline Total & 09 & 100 & 09 & 100 & 09 & 100 \\
\hline
\end{tabular}




\section{Continuação....}

\begin{tabular}{|c|c|c|c|c|c|c|}
\hline Precisão & $\mathrm{n}$ & $\%$ & $\mathbf{n}$ & $\%$ & $\mathbf{n}$ & $\%$ \\
\hline Sim & 09 & 100 & 09 & 100 & 89 & 08 \\
\hline Não & 00 & 00 & 00 & 00 & 00 & 01 \\
\hline Não respondeu & 00 & 00 & 00 & 00 & 00 & 00 \\
\hline Total & 09 & 100 & 09 & 100 & 09 & 100 \\
\hline Variedade & $\mathrm{n}$ & $\%$ & $\mathrm{n}$ & $\%$ & $\mathbf{n}$ & $\%$ \\
\hline Sim & 09 & 100 & 08 & 89 & 07 & 78 \\
\hline Não & 00 & 00 & 00 & 00 & 01 & 11 \\
\hline Não respondeu & 00 & 00 & 00 & 00 & 00 & 00 \\
\hline Total & 09 & 100 & 09 & 100 & 09 & 100 \\
\hline Credibilidade & $\mathrm{n}$ & $\%$ & $n$ & $\%$ & $n$ & $\%$ \\
\hline Sim & 07 & 78 & 08 & 89 & 08 & 89 \\
\hline Não & 02 & 22 & 01 & 11 & 01 & 11 \\
\hline Não respondeu & 00 & 00 & 00 & 00 & 00 & 00 \\
\hline Total & 09 & 100 & 09 & 100 & 09 & 100 \\
\hline
\end{tabular}

Quadro 3 - Comentários e sugestões dos especialistas no julgamento dos atributos dos itens que compõem os Indicadores de Avaliação de Controle e Prevenção de ITU Associada ao Cateter. São Paulo, 2005.

\begin{tabular}{|c|c|c|c|}
\hline Indicador & $\begin{array}{c}1 \text { - Indicação e Permanência } \\
\text { (IUIC) }\end{array}$ & $\begin{array}{c}2 \text { - Manutenção do cateter } \\
\text { Vesical (IUMN) }\end{array}$ & $\begin{array}{c}3 \text { - Infra-estrutura para } \\
\text { procedimento de CV (IUIF) }\end{array}$ \\
\hline Comportamental & $\begin{array}{l}\text { 1) Não mede a adequação da } \\
\text { indicação/manutenção. } \\
\text { 2) Depende da avaliação } \\
\text { registrada no prontuário. }\end{array}$ & 1) Falta técnica manutenção. & $\begin{array}{l}\text { 1) Reduzir número de itens e separar } \\
\text { estrutura/ processo no mesmo } \\
\text { indicador. }\end{array}$ \\
\hline Objetividade & Sem comentários. & Sem comentários e sugestões. & 1) Idem ao anterior. \\
\hline Simplicidade & Sem comentários e sugestões. & Sem comentários e sugestões. & $\begin{array}{l}\text { 1) Disponibilidade de material e } \\
\text { treinamento é sujeita a interpretações } \\
\text { variáveis. Ex. 1: volumes maiores de } \\
\text { urina na coleta; } \\
\text { ex. 2: treinamento (são diferentes } \\
\text { um anual para os recém admitidos e } \\
\text { um anual para todos os profissionais } \\
\text { do hospital). }\end{array}$ \\
\hline Clareza & Sem comentários e sugestões. & Sem comentários e sugestões. & $\begin{array}{l}\text { 1) Procedimentos assépticos para } \\
\text { limpeza. Não estão claros os itens: } \\
\text { reposição do sistema fechado e } \\
\text { volume maior de urina coletada pela } \\
\text { bolsa coletora. }\end{array}$ \\
\hline Pertinência & Sem comentários e sugestões. & 1) Falta técnica de manutenção. & Sem comentários e sugestões. \\
\hline Precisão & Sem comentários e sugestões & Sem comentários. & Sem comentários. \\
\hline Variedade & Sem comentários e sugestões. & Sem comentários e sugestões. & $\begin{array}{l}\text { 1) Materiais estéreis e com data de } \\
\text { validade no prazo poderiam estar } \\
\text { em um único item. }\end{array}$ \\
\hline Credibilidade & $\begin{array}{l}\text { 1) Falta pontuar os itens } \\
\text { considerados justificativas } \\
\text { válidas para SV. }\end{array}$ & 1) Falta Técnica manutenção. & $\begin{array}{l}\text { 1) Estão categorizados com o } \\
\text { mesmo peso itens que têm valores } \\
\text { distintos na prevenção de ITU. Ex.: } \\
\text { material estéril x cada item do } \\
\text { conteúdo do protocolo. }\end{array}$ \\
\hline
\end{tabular}


Tabela 4 - Valoração de relevância dos componentes do Indicador 3: Infra-estrutura para procedimentos com Cateterismo Vesical ( IUIF) São Paulo, 2005.

\begin{tabular}{|c|c|c|c|c|c|c|c|c|c|c|c|c|c|}
\hline \multirow{2}{*}{$\begin{array}{l}\text { Valoração } \\
\text { Cód. }\end{array}$} & \multicolumn{2}{|c|}{ Não respondeu } & \multicolumn{2}{|c|}{ (1) } & \multicolumn{2}{|c|}{ (2) } & \multicolumn{2}{|c|}{ (3) } & \multicolumn{2}{|c|}{ (4) } & \multicolumn{3}{|c|}{ Score } \\
\hline & n & $\%$ & $\mathbf{n}$ & $\%$ & $\mathbf{n}$ & $\%$ & $\mathbf{n}$ & $\%$ & $\mathbf{n}$ & $\%$ & $\mathbf{n}$ & Med. & Mod. \\
\hline IUIFTR & 3 & 33,3 & - & - & - & - & 2 & 22,2 & 4 & 44,4 & 9 & 3 & 4 \\
\hline IUIFME & 3 & 33,3 & - & - & - & - & - & - & 6 & 66,6 & 9 & 4 & 4 \\
\hline IUIFMD & 3 & 33,3 & - & - & - & - & 1 & 11,1 & 5 & 55,5 & 9 & 4 & 4 \\
\hline 4IUIFMG & 3 & 33,3 & - & - & - & - & 3 & 33,3 & 3 & 33,3 & 9 & 3 & 4 \\
\hline IUIFIJ & 3 & 33,3 & 1 & 11,1 & - & - & - & - & 5 & 55,5 & 9 & 4 & 4 \\
\hline IUIFNC & 3 & 33,3 & - & - & 2 & 22,2 & 4 & 44,4 & - & - & 9 & 2 & 3 \\
\hline IUIFMA & 4 & 44,4 & 1 & 11,1 & 1 & 11,1 & 2 & 22,2 & 1 & 11,1 & 9 & 1 & - \\
\hline IUIFLM & 3 & 33,3 & - & - & - & - & - & - & 6 & 66,6 & 9 & 4 & 4 \\
\hline IUIFTA & 3 & 33,3 & - & - & - & - & - & - & 6 & 66,6 & 9 & 4 & 4 \\
\hline IUIFTI & 3 & 33,3 & - & - & 1 & 11,1 & 1 & 11,1 & 4 & 44,4 & 9 & 3 & 4 \\
\hline IUIFTM & 3 & 33,3 & - & - & 1 & 11,1 & 1 & 11,1 & 4 & 44,4 & 9 & 3 & 4 \\
\hline IUIFTR & 3 & 33,3 & 1 & 11,1 & 1 & 11,1 & 1 & 11,1 & 4 & 44,4 & 9 & 2 & - \\
\hline IUIFLP & 3 & 33,3 & - & - & 1 & 11,1 & 3 & 33,3 & 2 & 22,2 & 9 & 3 & 3 \\
\hline IUIFFI & 3 & 33,3 & - & - & - & - & 1 & 11,1 & 5 & 55,5 & 9 & 4 & 4 \\
\hline IUIFFD & 3 & 33,3 & - & - & - & - & - & - & 6 & 66,6 & 9 & 4 & 4 \\
\hline IUIFRD & 4 & 44,4 & 2 & 22,2 & 1 & 11,1 & 1 & 11,1 & 1 & 11,1 & 9 & 1 & - \\
\hline IUIFTN & 3 & 33,3 & 1 & 11,1 & - & - & 3 & 33,3 & 2 & 22,2 & 9 & 3 & 3 \\
\hline IUIFAU & 3 & 33,3 & - & - & - & - & 1 & 11,1 & 5 & 55,5 & 9 & 4 & 4 \\
\hline IUIFVM & 4 & 33,3 & 1 & 11,1 & 1 & 11,1 & - & - & 3 & 33,3 & 9 & 2 & 4 \\
\hline
\end{tabular}

Legenda: (1) não relevante; (2) pouco relevante; (3) relevante; (4) muito relevante; $\mathrm{n}$ =número absoluto, \% percentual; Med. = mediana; Mod. $=$ moda 